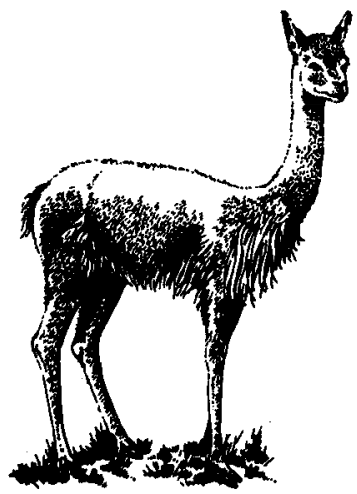

\title{
Guanacos in Peru
}

\section{William L. Franklin}

The guanaco, a wild South American camel, like the vicuña, is not on the IUCN endangered list, but numbers have decreased steadily, and it is on Peru's list of endangered species. The author, who describes a brief study of the largest population in Peru, suggests that protective measures are needed.

The guanaco Lama guanicoe and the vicuña Vicugna vicugna are the only members of the South American camel family that exist today in the wild state. The vicuña's historical distribution was in the highlands of the central Andes - the altiplano of Peru, northern Chile, western Bolivia, and north-eastern Argentina. Heavy poaching has severely reduced its numbers over the past two decades, and it appears in the IUCN Red Data Book as a vulnerable species. The guanaco's original range stretched from mid-Peru into parts of Bolivia, the length of Chile, on to the Patagonia pampas of southern Argentina, and south to Tierra del Fuego. Historically it has been, and remains today, most abundant in southern Argentina, but numbers are diminishing. Howard (1970) reported that guanacos have essentially been eliminated from the large Patagonian pampas, due to hunting and range deterioration, and are progressively being displaced from these open plains to the less accessible (foothill) scrub country. In Chile, where numbers have been greatly reduced since the Spanish Conquest in the 16th century, they survive on the southern pampas and the Chilean part of Tierra del Fuego (Miller et al., 1973).

The guanaco is more flexible than the vicuña in its habitat requirements. Guanacos are found from sea level up to 4000 metres (m.) in both warm and cold grasslands and in shrublands that are interspersed with forested areas (Miller et al., 1973), whereas the vicuña inhabits the cold and semi-arid short grasslands of the alpine altiplano between 3700 and $4900 \mathrm{~m}$. There appears to be little to no overlap in their distribution and habitat selection.

In Peru, guanacos were formerly common along the coastal region on the western upper slopes of the Andes where year-round sparse vegetation was available, as well as on the scattered tem- 
porarily vegetated 'lomas' created by winter fogs along the coastal plain (Grimwood, 1968a). Grimwood (1968b) reported that the guanaco was on the verge of extinction in Peru and that recent sightings were rare. Neither he nor other wildlife specialists working in Peru at the time (Pierret, 1966) were able to visit the one surviving large population on the isolated hacienda of Calipuy, reported by the owners to be between 400 and 500. This was America's most northerly population, at $8^{\circ} 30^{\prime} \mathrm{S}$. In 1971 the Peruvian government, on the advice of the Directory of Forestry, Wildlife and Lands, declared the guanaco a rare and endangered animal in Peru. As it did not occur in any of Peru's national parks or reserves, it was important to verify the status of the Calipuy population. The author and a team of assistants visited Calipuy from April 21 to May 6 1973 to determine status, numbers and distribution, and to make preliminary observations on social organisation and general ecology. Records of other wildlife species were also made.

\section{Study Area and Methods}

Calipuy is a 117,600 -hectare cattle and farming estate in the Andean sierra, in the District and Province of Santiago de Chuco, Department of La Libertad, and falls under the jurisdiction of the Ministry of Agriculture's Zone III. Access is difficult, by dirt roads from the coastal city of Trujillo into the mountains for $285 \mathrm{~km}$., then south $85 \mathrm{~km}$. by mule via Calipuy village to the hacienda's grazing district of Guanacón (also called El Temple). Guanacón (Quechua for 'many guanacos') is a 30,000-hectare area on the western slope of the Andes that drops sharply from $4000 \mathrm{~m}$. to about $1000 \mathrm{~m}$. in less than $10 \mathrm{~km}$. For the four to five months of the summer growing season and on into the early dry season (March-June and, in favourable years, July), the hacienda's 4100 head of range cattle are grazed in Guanacón, a country of deep valleys with steep slopes drained by streams and rivulets that flow only briefly during the summer rainy season. The western slope of the Central Andes is dry because of the cold coastal Peruvian Current and the Andean 'rain barrier' to the prevailing easterlies off the Amazon Basin. Specific climatological information for the area is lacking, but the annual average precipitation varies from $1000 \mathrm{~mm}$. to $200 \mathrm{~mm}$. (Tosi, 1960), becoming drier from east to west as the elevation rapidly drops off towards the desert coastal plain.

Following Holdridge's system of natural life zone classification, the plant formations found in Guanacón in decreasing elevation were: mountainous prairie, sub-humid mountain steppe, lower mountain dry forest, semi-arid lower mountain spiny steppe, spiny subtropical forest, and arid brushy subtropical desert (Tosi, 1960). Guanaco distribution was centred in the sub-humid mountain steppe, lower mountain dry forest, and semi-arid lower mountain spiny steppe.

Shrubs (woody perennials) dominated the plant community; occasional small clearings on the flattened parts of ridges were vegetated with grasses and forbs. Transects on the crest and slopes of 


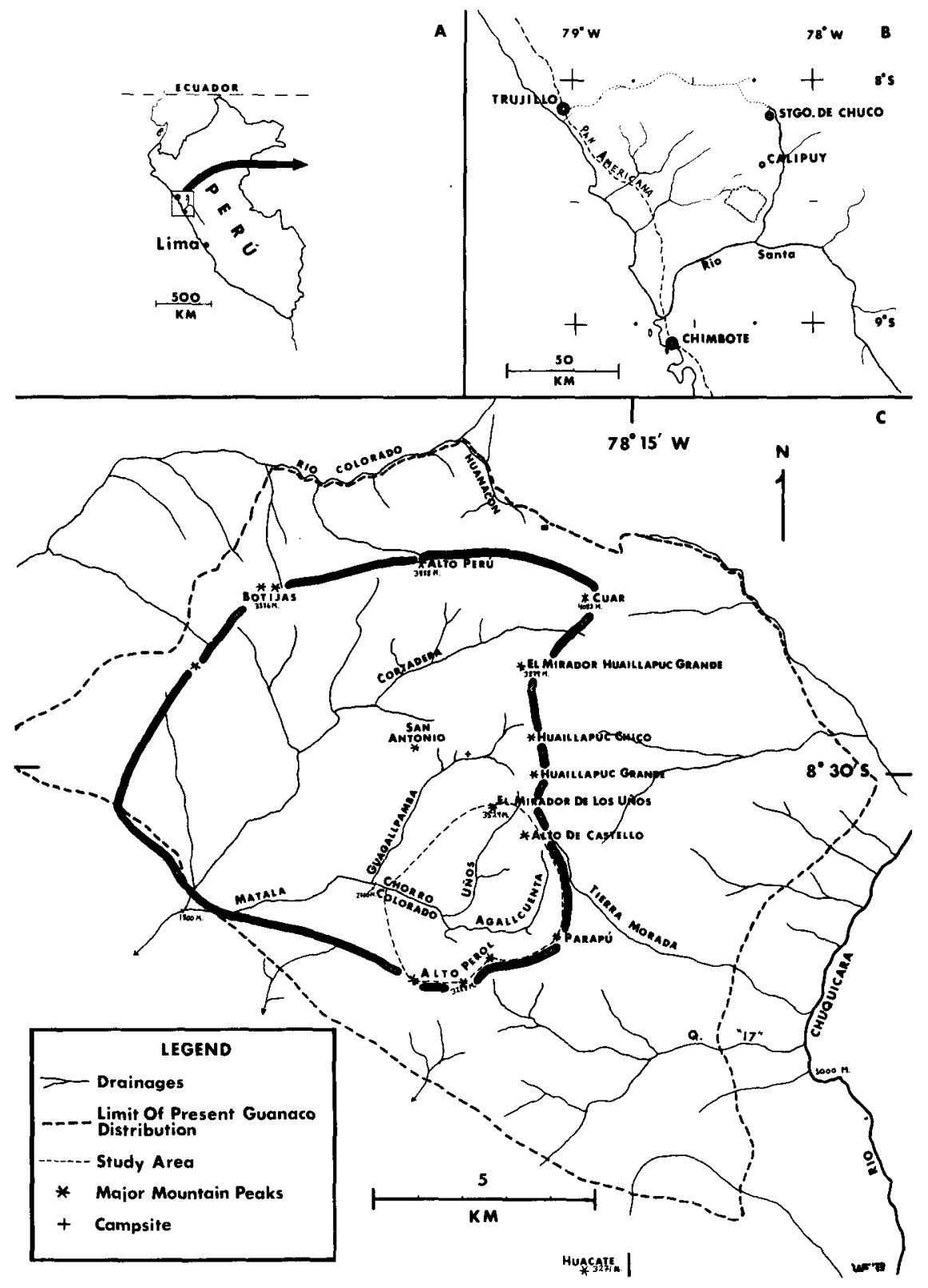


El Mirador de los Unos by the Line Intercept method $(325 \mathrm{~m}$. analysed) showed that open-bare ground covered 58.2 per cent, shrubs 28.3 per cent and grasses-forbs 10.4 per cent (Table 1). The dominant plant species were composites, yellow-flowering shrubs of the genera Coreopsis with a forb and grass understory of Plantago, Eragrostis, and Stipa.

Our expedition camped at the Guagallpamba Cave to census and observe guanacos in the Unos, Agallcuenta, and Chorro Colorado drainages (Fig. 1C). The 1200-ha. study area ranged from $2700 \mathrm{~m}$. up to $3529 \mathrm{~m}$. The peaks El Mirador de los Unos $(3529 \mathrm{~m}$.) and Alto del Castello were used as observation points overlooking the study area (Fig. 2). Observations were made with binoculars and spotting scopes $(20 \times$ and $30 \times)$.

\section{The Calipuy Guanaco}

Isolation has been a key factor in the survival of the Calipuy guanaco population, together with the protection given by the hacienda's owners and managers over the past twenty years. The guanaco have been undisturbed, apart from an occasional hunt by guests and the permitted killing for food by herders during cattle roundups. An outbreak of foot and mouth disease in the hacienda's cattle in 1963-65 affected the guanaco, and it was not uncommon for riders to find guanaco carcasses and skeletons, apparently victims of the disease.

The guanacos leave those parts of the Guanocón section of the hacienda that are being grazed by cattle from March through June, apparently disturbed by them and also by horsemen patrolling the region daily. When we were there in late April and early May we saw no guanacos where cattle were being grazed (Cortadera and Guagallpamba drainages), but they were common in the drainages to the south where, owing probably to the absence of drinking water and sparsity of forage, there were no cattle (Unos, Chorro Colorado, and Agallcuenta).

\section{Numbers and Distribution}

This seasonal retreat of guanacos into a relatively concentrated area gave us an opportunity to assess their numbers and status. Although numbers were reported to be smaller to the east, west, and south, the study area had the highest density at that time of year: over four days we saw $64,62,101$, and 99 , the last two days being the most representative. Roughness of the terrain undoubtedly caused us to overlook some animals. We estimated the actual number in the 1200 hectare study to be closer to 150 (density $=1$ guanaco $/ 8$ hectares). The reliable guides and riders who worked and lived in Guanacón (Fig. 1C), gave us information about the distribution outside the study area which we checked in those areas we were able to visit. The best indicator was the presence of 'majadas'-dung piles in the grassforb clearings. These were common in Guagallpamba and Cortadera canyons, present in Huanacón, and sparse on the slopes of the Rio Colorado drainage. Majadas found in those areas where we found 


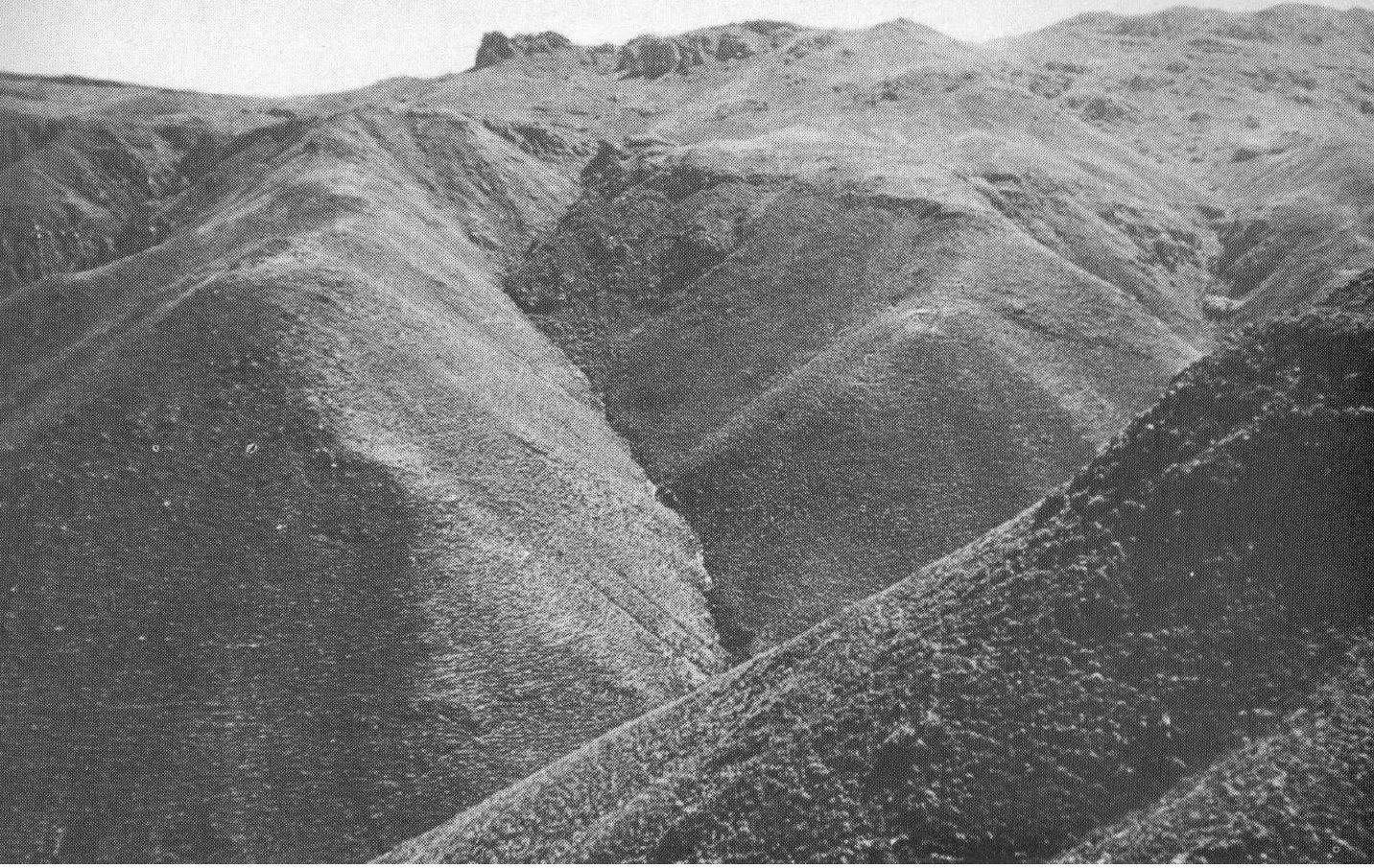

\section{LOOKING NORTH IN GUANACON-CALIPUY}

no guanacos supported the reports that after cattle have been moved out of Guanacón, guanacos move north out of the Unos, Chorro Colorado, and Agallcuenta drainages (study area), into the Guagallpamba, Cortadra (Fig. 3), and Huanacón drainage systems.

The maximum annual range of 19,200 hectares where guanacos are presently found (although not on a year-round basis because of displacement by man-cattle), represents 64 per cent of the 30,000 ha. Guanacón grazing district and 34 per cent of the hacienda's 56,700 hectares of natural pasture. We estimated the total number here to be between 300 and 500 (1 guanaco/64-38 hectares). Before the foot-andmouth epidemic the owner estimated he had approximately 1000 guanacos on his land (Grimwood 1968a), but by 1965 only 400 to 500 were believed to remain. Our estimate suggests that the population has maintained itself since 1965.

\section{Population Structure}

Of the 326 guanaco sightings we made during our four days in Guanacón, 74 per cent were in family groups, 17 per cent in male groups, 6 per cent were solitary males (Fig. 4), and 3 per cent in unknown (undetermined) groups. Family groups consisted of an adult male and females with or without young ('chulengos'). Unfortunately, it is impossible to sex South American wild camelids in the field. Behavioural differences are the only quick guide but whenever possible we verified an animal's sex by its genital organs when it was defecating-urinating, rolling over while dusting, or raising its tail during behavioral interactions with other animals.

Family group size ranged from 2 to 13 and averaged $7.1(n=34)$. 
Two-year-olds were nearly indistinguishable from adults and were classified as adults. Yearlings ( $>1$ to $<2$ years-old) were larger, had darker faces and narrower muzzles than juveniles. Juvenile $(<1$ year-old) were smaller with lighter coloured faces, heads and bodies than one-year-olds. The age of individuals on the border between old-juveniles and young yearlings was the most difficult to determine. For family groups in which the complete composition was determined ( 24 groups with 132 individuals), there was a ratio of 34 juveniles : 100 adult females, and 47 yearlings: 100 adult females.

Females about one month or less from parturition could be visually assessed as pregnant. In ten groups for which we got the complete composition, with 42 adult females, two females had one to two-weeks-old-juveniles at their sides and 22 others were pregnant. Thus 57 per cent $(24 / 42)$ of the females would be giving birth within a two-month period (mid-April to mid-June). Three other recently born juveniles were seen (two 3-4 weeks-old and one 3-5 days-old). These observations suggested a birth season for nearly 60 per cent of the females during the months of April, May and June. Schmidt (1973) reported that 74 per cent of all births by captive guanacos in northern zoos occurred from May to August; guanaco births at the Adelaide Zoo in South Australia showed a tendency for peaks in August (25 per cent of all births) and in December-January (44 per cent). The birth season for vicuñas in Peru spans midFebruary to late April (Franklin, 1974b).

Male group size ranged from 5 to 17 and averaged $10.6(n=5)$. For the five male groups seen, three were mostly composed of subadults (one- to two-years-old): 6 of 6,5 of 5 , and 6 of 9 . As noted above, 6 per cent of all guanacos seen were solitary males (actually 6.4 per cent, $21 / 326$ ). This is an unusually high percentage compared to the vicuña. In the 1968 and 1971 vicuña censuses made by the senior author in Peru's Pampa Galeras National Vicuña Reserve (Franklin, 1973), only 0.2 per cent $(2 / 891)$ and 1.1 per cent $(13 / 1217)$ were solo males. Solitary adult vicuña males usually have an established territory and need females to form a family group (Franklin, 1971).

\section{Behaviour}

Isolated behaviour observations are often of limited value without a broader picture of how they fit into the species' behavioural ecology. To add to the interpretative value of our observations on guanaco behaviour, I have compared them with the closely related vicuña based upon studies (Franklin, 1974a and 1947b).

\section{Habitat}

1. The guanaco occupied a rugged and arid terrain of steep ravines and $\mathrm{V}$-shaped valleys, lightly to heavily vegetated by shrubs with a sparse understory of grasses and forbs. (Vicuñas occupy flat to gently rolling terrain dominated by perennial grasses and forbs.) 2. Guanacos both grazed (on grasses and forbs) and browsed (on shrubs). Periodic spot checks revealed that feeding animals grazed 
60 per cent and browsed 40 per cent of the time. On several occasions they were seen selectively eating the yellow composite flowers from shrubs (Coreopsis sp.). (Vicuñas are strictly grazers and were never observed to browse.) This important difference between the two species permits the guanaco to inhabitat both grasslands and shrublands.

3. The guanacos were in a waterless zone, but had access to water from seepages scattered along the Guagallpamba stream bed. We saw some groups moving to and from Guagallpamba, but were unable to determine the frequency of these watering visits for any one group. (Vicuña habitat has water immediately available or easily accessible from springs or streams.)

4. Family groups spent a large portion of their time on prominent flattened ridges. Solo males were almost always seen on conspicuous narrow ridges separating ravines. The guanacos were quite capable of travelling in this rough terrain. On one occasion a family group of 11 was seen traversing a $65^{\circ}-70^{\circ}$ earth slope with ease; some of the young were even running and playing. (The climbing and traversing ability of vicuña was not observed because of the flatness of their habitat.)

5. Family groups had a flight distance of up to two kilometres, usually retreating by trotting or running in the opposite direction. In contrast, solo males were much more tolerant of people and could be approached as close as 200 to $300 \mathrm{~m}$. (Vicuña in the Pampa Galeras Reserve can be approached on foot to within 200 to $500 \mathrm{~m}$., but in other locations they have been just as quick to take flight as the guanaco were in Guanacón.)

\section{Inter-Group Interactions}

1. Six observations were made of a family-group male aggressively chasing another family group. For example, on May 11973 the male of Group 15 with a composition of 7 (1-4-1-1) chased at a run Group 12-consisting of three animals (1-0-2-0)-for $200 \mathrm{~m}$. downhill away from his group. (Group composition $=$ total animals (adult males - adult females - yearlings - juveniles.)

2. Three incidents were seen of solitary males involved in intergroup aggressive encounters with family groups. An example: on April 30 a single male chased a group of $9(1-?-$ ?-2) $100 \mathrm{~m}$., forcing them to cross a dry stream bed during their retreat.

3 . Twice solitary males were seen chasing male groups; in one a group of 17 were chased for 52 minutes over a distance of one kilometre before they disappeared into a gully. The adult male would trot into the male group with his head and neck lowered to slightly above horizontal, ears forward and tail in an upward curl. He repeatedly singled out one or two individuals chasing them in erratic circles over a 4-6 hectare area. No contact was made.

Observations were too few to determine whether such aggression involved the defence of a site, i.e. a territory. Some family groups were seen from one day to the next in the same general area, but more observations are needed to decide whether this was a territory 


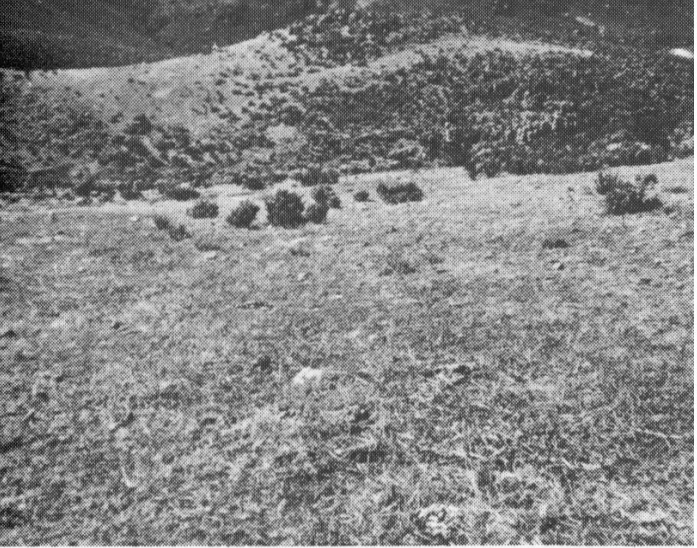

Guanaco dung pile; the surrounding grass-forb openings may be caused by dung piling and the resultant EIV. Two EIV-clearings are conspicuous on the ridges in the background.

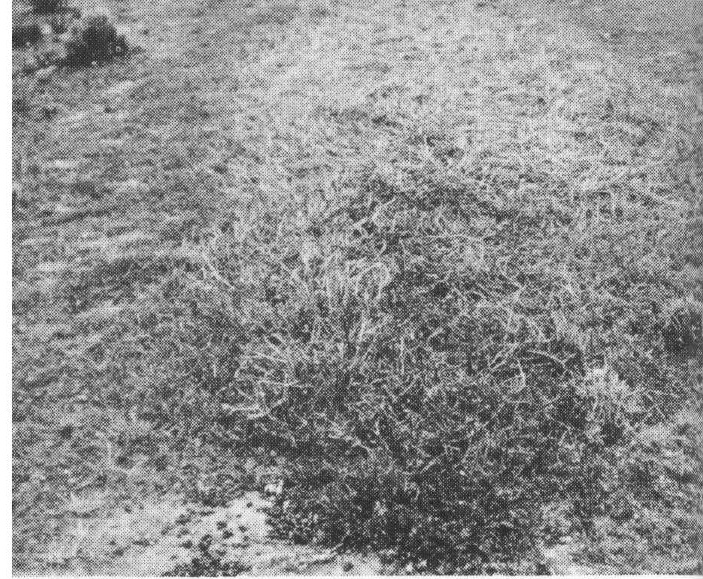

Aguanaco dung pile and the associated EIV. Long-term accumulation and subsequent downhill washing of organic matter and nutrients has accelerated soil development and plant succession.

being defended, or a 'group distance' (without reference to a permanent location) being maintained. (Each vicuña family group maintains an exclusive feeding and sleeping territory on a year-round basis. Inter-group aggressive encounters, in defence of their territories against trespassing family and male groups, are common.) It is possible that if guanacos are territorial, they may not use their territory as regularly as the vicuña (daily), nor on a year-round basis.

\section{Intra-Group Interactions}

1. We observed nine cases of escape by family groups. In six cases an attacking adult male was the cause; in three cases the cause was unknown. Invariably, an adult female was at the front of the group, and the adult male was last. Once the male actively forced his group along; another time the male appeared to be maintaining position between his group and the attacking male. (Vicuña have the same type of escape-retreat pattern.)

2. Tail wagging and flagging appears to be a common component of guanaco social communication. (This is also true of the domesticated llama.) For example, once when two adults from the same group became temporarily separated, the second animal ran up to the first. The two stood nearly nose to nose with their tails moving horizontally or in a U-pattern. (Vertical tail movement by the vicuña from downward to forward curls is common during aggressive interactions between individuals. Horizontal or U-flagging movement like that of the guanaco is not involved when individuals interact. However, it is often done by pregnant females that are within a few days of parturition.)

3. Several observations were made of family group males attempting to force individuals out of or into their group. On May 21973 we observed the following:

'Adult male (AM) of Group 32 actively pursuing two subadults (1-2 years-old) and trying to chase them back in his group. Believe one to be a subadult male (SAM) and the other a subadult female (SAF), but too far away to be verified. AM more intent on SAF, but not successful and 
his group then had three members (3(1-1-0-1)). 0914- the two subadults grazing $250 \mathrm{~m}$. from Group 33, AM-33 walked over to the two and chased the SAM. AM chasing the SAM at a hard run away from the group, AM with his neck/head horizontal to ground, SAM with head up and tail in downward curl. Chase lasted two minutes over $1 \mathrm{~km} .0917$ - AM walked back toward his group, on way he met the SAF, nosed at her hindquarters, SAF horizontal tail wagging, SAF moves away from AM, AM begins walking back to his group again, the SAF follows him (AM checking SAF for oestrus?). 0925 - AM actively chasing the SAF toward his group, biting at her hindlegs and rear flank and again nosing (smelling?) at hindquarters ...'AM vicuña have been seen on many occasions forcing subadult and adult females out of and into their groups.

4. An interesting sequence took place on April 30 between the adult male and two members of Group 1 that were either old-juveniles or young yearlings (referred to here as Yearling One (Y1) and Yearling Two (Y2)):

'Two yearlings approached the AM with their tails in forward curls, submissive in nature, especially $\mathrm{Y} 1$, the AM smelled its hindquarters. Y1 verified to be a male while dusting. Y1 approached Y2 who was lying down. Y1 smelled and licked hindquarter of Y2, Y2 tail in forward curl, flehmen three times by $\mathrm{Y} 1$ with head tilted high and back without curling lips, Y2 (strongly suspected to be a female) returned with a Below Horizontal Ear Threat (BHET) (Franklin, 1974b), got up and walked away to the AM. Y2 smelled his hindquarters, AM turned head around and gave BHETs, AM finally got up and walked away. Fifteen minutes laterthe AM approached an adult female (AF) with a juvenile (both lying down) and an AF with a yearling (actually a near yearling, probably an oldjuvenile). The yearling (Y) moved to the opposite side of her own AF and dropped into a submissive posture with its ears horizontal, head lowered to the level of its back, legs slightly bent, neck not curled backward (as the Submissive Crouch posture of juvenile vicuñas (Franklin, 1974b)). $\mathrm{AM}, \mathrm{AF}$ \& juvenile motionless for 15 seconds in frozen standing positions, all with ears horizontal. AF and $Y$ start to walk away, AF gives three separate threats to the AM: one Head Up Tilt Threat (Franklin, 1974b), and two BHETs with head-swing in direction of AM. AF \& Y walk away with $Y$ on opposite side of AF, away from AM. The $Y$ was believed to be an old-juvenile male, but we were unable to verify it.'

Interactions between the adult male of the vicuña family group with a juvenile male and its mother are common when the juvenile is $8-10$ months-old. The juvenile male is submissive to the antagonistic male, while the female is defensive of her young. Eventually, the adult will forceably expel the juvenile from his group. The same sort of juvenile male expulsion might well take place in guanaco family groups.

5. Guanaco were seen using dung piles for defecation-urination. Each time, the animal smelled the dung pile before positioning itself over the pile. In a ravine between our camp site and the Huaillapuc Grande peak there was an unusual abundance of guanaco dung piles and the associated downhill pattern of Excrement Influenced Vegetation (EIV) (Fig. 5). Vicuña also use dung piles for defecation and urination. This appears to serve a short-term primary function of territory marking, especially for intragroup orientation; a long term 
secondary effect has been vegetational changes in the vicuña's habitat. The long-term accumulation of excrement and urine results in EIV around their dung piles too. The downhill rain washing of organic matter and nutrients causes an acceleration of soil development and plant succession (Franklin, 1973 and 1974b). The ravine had 18 dung piles and surrounding EIV at a density of 3.5 dung piles/hectares (vs. 6.8 dung piles/hectare in vicuña sleeping territories, and 4.8 dung piles/hectare in vicuña feeding territories). Dung piles were spaced an average of $32 \mathrm{~m}$. apart and the surrounding EIV was an average of $4 \mathrm{~m}$. wide by $15 \mathrm{~m}$. long. Dung piles were at the top of the EIV line with the greatest width of EIV at the dung pile that then tapered down toward the bottom. The outer region of the reverse tear-shaped EIV was a low $(10-20 \mathrm{~cm})$ dense growth of Erodium sp. and Eragrostis sp. The centre was dominated by tall growing $(20-30 \mathrm{~cm}$.) Erodium cicutarium, but species of Urocarpidium and Chenopodium were also present. Some excrement was scattered between the main dung piles, indicating that the piles were sometimes not used. (Vicuña always used established dung piles.)

Guanaco dung piles were also found, together with EIV and the dominant Erodium c. (Fig. 6), in the occasional clearings between the shrubs, on the upper part of the Guagallpamba drainage and the slopes of Cortadera. These flattened clearings and their associated EIV (EIV-Clearings) may well be a focal point and/or sleeping site for a family-group territory. The forb-grass clearings in the shrub community are believed to be the result of the long-term deposition and dispersion of organic matter and nutrients from the dung piles. In Fig. 3 of Cortadera drainage, some EIV-Clearings can be seen on the opposite slope as faint light spots. These were the cattle's favourite bedding and resting places when the guanaco were not there.

\section{Interactions With Other Species}

1. On April 30 several family groups were feeding on the lower ridge separating the Guagallpamba and Unos drainages. The following day scattered small groups of cattle were there, and only one guanaco family group. For nearly half an hour a cow grazed within $10 \mathrm{~m}$. of the family group, which moved away a few metres; no other overt behavioral responses were seen. It appeared that the guanaco had moved elsewhere when they found cattle in the area that morning.

2. The sudden appearance of a spectacled bear Tremarctos ornatus through the underbrush, within $200 \mathrm{~m}$. of a feeding and resting guanaco family group, sent them in quick flight in the opposite direction. However, when the bear crossed paths with a small group of cattle, he appeared very apprehensive and quickly moved away.

\section{Other Wildlife Species}

A list of the bird species observed during our four day stay in Guanacón and their relative abundance was compiled by R. T. Paul of the US National Audubon Society. The Andean condor is uncommon, but was regularly seen each day. (The list is available upon request from the author.) 
Table 1. Vegetation composition. Line intercept transects totalling 325 metres were done on the crest and slopes of the mountain El Mirador de los Unos and the upper Guagallpamba drainage in the Guanacón study area.

\begin{tabular}{|c|c|c|}
\hline Surface-Type & $\begin{array}{c}\text { Metres } \\
\text { Measured }\end{array}$ & $\begin{array}{c}\text { Absolute } \\
\text { Percent Cover }\end{array}$ \\
\hline $\begin{array}{l}\text { Open-Bare Ground } \\
\text { Shrubs } \\
\text { Grass \& Forbs } \\
\text { Surface Rocks }\end{array}$ & $\begin{array}{r}189.0 \\
92.1 \\
33.9 \\
10.0\end{array}$ & $\begin{array}{r}58.2 \\
28.3 \\
10.4 \\
3.1\end{array}$ \\
\hline Surface Rocks & 325.0 & 100.0 \\
\hline Shrubs & & $\begin{array}{c}\text { Relative } \\
\text { Percent Cover }\end{array}$ \\
\hline $\begin{array}{l}\text { Coreopsis sp. } 3 \\
\text { Coreopsis sp. } 2 \\
\text { Composite Shrub } 4 \\
\text { Baccharis sp. } 1 \\
\text { Miscellaneous shrubs (10 species) }\end{array}$ & $\begin{array}{r}48.2 \\
22.5 \\
8.8 \\
3.8 \\
8.8\end{array}$ & $\begin{array}{ll}52.3 \% & 76.7 \\
24.4 & \\
9.6 & \\
4.1 & \\
9.6 & \end{array}$ \\
\hline & 92.1 & 100.0 \\
\hline
\end{tabular}

By far the most exciting large mammal was the single spectacled bear, a rare and endangered species, observed for about twenty minutes on May 1 in the study area, between the lower ends of the Guagallpamba and Unos drainages. One sighting was made of the common Andean fox Dusicyon culpaeus at midday on May 2.

The occurrence of both the spectacled bear and the guanaco in the same locality emphasises the importance and uniqueness of the Guanacón-Calipuy area.

\section{Recommendations}

1. In Peru and Chile the guanaco is an endangered species, and in Argentina it is rapidly diminishing. It is likely soon to become an endangered species on a continental, and thus international basis. Protective management is needed now to prevent it following the same road as the vicuña.

2. The Calipuy-Guanacón area is recommended for consideration as a National Guanaco Reserve. This remote and wild region contains the largest remaining population in Peru, as well as other indigenous fauna (spectacled bear, Andean condor, etc.) and flora typical of the arid western slope of the Central Andes. Calipuy is also the northernmost guanaco population.

3. The present investigation assessed the status and distribution of the Calipuy guanaco population when they had seasonally been displaced from part of their range by the activities of man and cattle. A more comprehensive survey is suggested at a time of year when the cattle are off the Guanacón grazing district in order to determine: (1) the full range occupied by the guanaco when not influenced by 
man and cattle, and (2) the extent of range overlap between guanaco and cattle.

4. The location, size and boundaries of a reserve are beyond the scope of this preliminary study, but the Cortadera, Guagallpamba, Chorro Colorado, Unos, and Agallcuenta drainages, being in the centre of the present guanaco distribution, are especially important. Collectively they enclose a biologically natural unit covering approximately 7200 hectares.

5. Information on the guanaco is sorely lacking. Their relative abundance in Guanacón makes it a unique area for field biological research on the species. Year-round distribution, habitat preferences, food habits, water requirements, and the degree of competition with domestic livestock are some of the pertinent questions that need to be examined.

\section{Acknowledgments}

The project was under the auspices of and financially supported by Educational Expeditions International (EEI). Staff members R. L. Hunter, T. Kittel, and R. T. Paul contributed greatly to the field work. We were energetically assisted by expedition members David Bruton, Kathy Finley, Karl Guter, and Nancy Ward. Special thanks are expressed to: Cesar A. Ganoza, General Administrator of SAIS 'Libertad'-Estate Calipuy, and his wife for their generous cooperation and warm hospitality that made our expedition possible; to our knowledgeable guide Lorgio Pereda Corro; to the President and members of SAIS 'Libertad' Itda. No. 18 for their valuable assistance; to Dr Oscar Tovar of the Museum of Natural History in Lima for plant identification; and to Robert and Vicky McDowell for their friendship and help. The author is a Research Associate of Foresta Institute for Ocean and Mountain Studies.

\section{Literature Cited}

FRANKLIN, W.L. 1971. Vicuña survey, Peru. In World Wildlife Yearbook 1970-71 (pp. 145-148). Morges.

1973. Conservation of the vicuña in Peru. In World Wildlife Yearbook 1971-73 (pp. 209-212). Morges.

1974a. The social behaviour of the vicuña in The Behavior of Ungulates and its Relation to Management (pp. 477-487). Ed. V. Geist. IUCN, Morges.

1974b. Effects of habitat and social organization upon vicuña population density. In Manuscript.

GRIMWOOD, I. 1968a. Endangered mammals in Peru. Oryx 9 (6):411-421.

1968b. Appendix III to recommendations on the conservation of wildlife and the establishment of national parks and reserves in Peru. Brit. Min. of Overseas Develop. 100 pp.

HOWARD, W.E. 1970. Relationship of wildlife to sheep husbandry in Patagonia, Argentina. Unpubl. FAO Report, Proj. No. 14. $31 \mathrm{pp.}$

MILLER, S., J. ROTTMAN, and R. D. TABER. 1973. Dwindling and endangered ungulates of Chile: vicugna, lama, hippocamelus, and pudu. N. Am. Wildl. Conf. 38:55-68.

PIERRET, P.V. 1966. The fauna of northern Peru, present status and future. Inst. of Forestry Invest., Lima. Unpubl. Report in Spanish. 13 pp.

SCHMIDT, C.R. 1973. Breeding seasons and notes on some other aspects of reproduction in captive camelids. Intern. Zoo Yearbook 13:387-390.

TOSI, J.A. 1960. Zonas de vida natural en el Peru. Inst. Interam. de Ciencias Agricolas de la OEA, Zona Andina. Bol. Tec. No. 5, $271 \mathrm{pp.}$

Present Address of Author: Department of Wildlife Science, Utah State University, Logan, Utah 84322 , USA 